“( 2015 IEEE. Personal use of this material is permitted. Permission from IEEE must be obtained for all other uses, in any current or future media, including reprinting/republishing this material for advertising or promotional purposes, creating new collective works, for resale or redistribution to servers or lists, or reuse of any copyrighted component of this work in other works." 


\title{
An Adaptive Neuro-Fuzzy Controller for Maximum Power Point Tracking of Photovoltaic Systems
}

\author{
Mahlagha Mahdavi ${ }^{1}$, Student Member, IEEE, $\mathrm{Li} \mathrm{Li}^{1}$, Member, IEEE, \\ Jianguo Zhu ${ }^{1}$, Senior Member, IEEE, and Saad Mekhilef ${ }^{2}$, Member, IEEE \\ ${ }^{1}$ Centre of Green Energy and Vehicle Innovation, University of Technology Sydney, Ultimo, NSW 2007, Australia \\ ${ }^{2}$ Department of Electrical Engineering, Faculty of Engineering, University of Malaya, $50603 \mathrm{KL}$, Malaysia \\ Mahlagha.MahdaviAghdam@student.uts.edu.au
}

\begin{abstract}
This paper presents a high performance tracking method for maximum power generated by photovoltaic (PV) systems. Based on adaptive Neuro-Fuzzy inference systems (ANFIS), this method combines the learning abilities of artificial neural networks and the ability of fuzzy logic to handle imprecise data. It is able to handle non-linear and time varying problems hence making it suitable for accurate maximum power point tracking (MPPT) to ensure PV systems work effectively. The performance of the proposed method is compared to that of a fuzzy logic based MPPT algorithm to demonstrate its effectiveness.
\end{abstract}

Index Terms-Maximum Power Point Tracking (MPPT), Adaptive Neuro-Fuzzy Inference Systems (ANFIS), Photovoltaic (PV) Systems, Fuzzy Logic Controller (FLC)

\section{INTRODUCTION}

The fast growth of worldwide electricity consumption has raised a great demand for power generation from renewable energy sources (RESs). RESs are extremely dependent on topographical location and climate conditions, as they are vibrant in nature [1]. In our world, the sun is the largest RES. Photovoltaic (PV) cells are developed to transform sunlight directly into electricity. The characteristics of PV cells are such that for a given solar insolation, each cell has a unique operating point, in terms of the output voltage and current, that can extract the maximum power from the cell. As the solar insolation varies, a special algorithm known as the maximum power point tracking (MPPT) is required to get the most power out of the cell. Since the maximum power point of a PV system leans on the temperature, irradiance, and shading or obstruction due to the clouds vastly [2], it is required that the MPPT algorithm must be adaptive and robust.

Among the various MPPT techniques of different control methods, control variables, circuitry, convergence speed, application, complexity, cost, and efficiency, etc. developed in the last few decades [3-6], the most common technique is the perturbation and observation $(\mathrm{P} \& \mathrm{O})$ method which has been widely employed because of its simple feedback structure and less measured parameters required. There are two types of $\mathrm{P} \& \mathrm{O}$ techniques; one has a perturbation occurring in the operating voltage of PV array, while the other in hill climbing on the duty cycle of the power converter, but both methods have weakness when the weather varies quickly [3].

Artificial intelligence, such as the fuzzy logic (FL), artificial neural network (ANN), and Neuro-Fuzzy, methods have had a great impact on development of new MPPT approaches [5]. While the ANN method has potent skill for plotting input and output of non-linear function though it lacks the heuristic sense, the FL method has the ability of converting linguistic and heuristic into numerical values through fuzzy membership functions and rules. These controllers can be applied for modeling, calculation, optimization and simulation of complex system to handle inaccurate inputs and have an overall rapid convergence [7].

This paper presents an adaptive Nuero-Fuzzy controller for MPPT of PV systems. Section II modes and analyses the performance of a PV cell. In Section III, a DC-DC converter is analyzed, and in Section IV, the proposed MPPT controller is presented in detail. Section $\mathrm{V}$ presents the numerical simulation and results. Finally, conclusions are drawn, and the future works are suggested in Section VI.

\section{PV MODEL AND ANALYSIS}

\section{A. Modeling of PV Module}

A general mathematical model and explanation of I-V curve for solar modules have been contrived for over half a century. There are several equivalent circuit based model for PV cells, and most of them include diodes, current source for photon current, series and parallel resistances that describe an interior resistance to the current flow and leakage current respectively [8].

Table I tabulates the electrical data of a PV panel under the standard test condition (STC) with the ambient temperature of $25^{\circ} \mathrm{C}$, the radiation of $1 \mathrm{Kw} / \mathrm{m}^{2}$, and the air 
mass of $1.5 \mathrm{Kg} / \mathrm{m}^{3}$. Fig. 1 depicts the general model for analyzing and simulating the PV system. It is preferred to eliminate parallel resistance $R_{P}$ due to its less influence on efficiency.

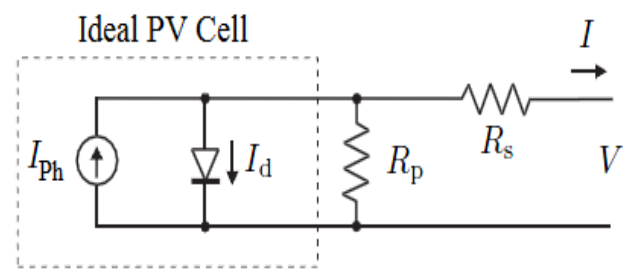

Figure 1. General PV Cell Model

The PV cell output current, I, can be derived as below,

$$
\begin{gathered}
I=I_{p h}-I_{d} \\
I_{d}=I_{O}\left[e^{\left(\frac{q V+I R_{S}}{a k T}\right)}-1\right]
\end{gathered}
$$

where $I_{p h, \text { cell }}$ is the photon generated current, $I_{d, \text { cell }}$ the diode current, $I_{O, \text { cell }}$ the reverse or leakage saturation current of diode, $\mathrm{q}$ the constant electron charge $\left(1.60222 \times 10^{-19} \mathrm{C}\right), \mathrm{K}$ the Boltzmann constant $\left(1.3806 \times 10^{-23} \mathrm{~J} / K\right), T$ the temperature (in Kelvin) of p-n junction of the cell, and $a$ the coefficient of diode's ideality $(1 \leq a<2)$.

A module or panel is formed by connection a number of cells in series, and the output current I for a module is:

$$
I=I_{p h}-I_{O}\left[e^{\left(\frac{\frac{V}{N_{S}}+I . R_{S}}{\alpha \cdot V_{t}}\right)}-1\right]
$$

where $\mathrm{N}_{\mathrm{S}}$ is the number of series connected cell, and

$$
V_{t}=\frac{K \cdot T}{q}
$$

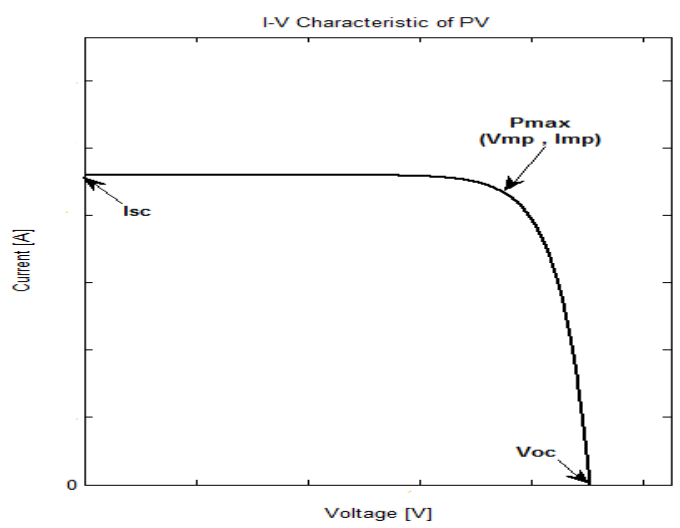

Figure 2. A typical I-V Curve

Fig.2 illustrates a typical I-V curve of a general module. There are three remarkable points in the curve as, the short circuit current $I_{S C}$, the open circuit voltage $V_{O C}$, and the maximum power point (MPP). Since $I_{p h}$ is much greater than the diode current, $I_{S C}$ is approximately close to $I_{p h}$. However,
$V_{O C}$ occurs when the output current is zero. The I-V characteristic depends on the parallel and series resistances, temperature, irradiation, and amount of incident light, which will be considered later.

In (3), $I_{p h}$ and $I_{O}$ can be calculated by the following equations:

$$
\begin{gathered}
I_{p h}=G \times\left[I_{s c n}\left(1+K_{i} \times \Delta T\right)\right] \\
I_{O}=I_{O n}\left(\frac{T_{n}}{T}\right)^{\frac{3}{a}} \times e^{b\left(\frac{1}{T_{n}}-\frac{1}{T}\right)} \\
b=\frac{E_{g} \times q}{a \times k} \\
I_{O n}=\frac{I_{S c n}}{e^{\frac{V_{O C}}{a . V} t}-1}
\end{gathered}
$$

where $\Delta T$ is the difference between the ambient temperature $T$ and the nominal temperature $T_{n}, K_{i}$ the temperature coefficient of $I_{S C}, G$ the radiation from the sun in $\mathrm{Kw} / \mathrm{m}^{2}, E_{g}$ the polycrystalline silicon band gap energy $(1.12 \mathrm{eV}), I_{O n}$ the nominal saturation current, and $I_{s c n}$ the nominal short circuit current.

One of the easiest ways to obtain $R_{S}$ is from the slope of the I-V characteristics at the open circuit voltage as

$$
R_{S}=-\left.\frac{d V}{d I}\right|_{V_{O C}}-\frac{V_{t}}{I_{O n} e^{\left(\frac{V O C}{V_{t}}\right)}}
$$

where the ideal $a=1$ is used.

By using (3), the output power can be determined as

$$
P=V I_{p h}-V I_{O}\left[e^{\left(\frac{\frac{V}{N_{S}}+I R_{S}}{\alpha \cdot V_{t}}\right)}-1\right]
$$

The MPP happens when $\frac{d P}{d V}=0$, that is:

$$
\exp \left(\frac{V_{m p p}}{N_{s} \cdot V_{t}}\right)\left[\left(\frac{V_{m p p}}{N_{s} \cdot V_{t}}+1\right)\right]=\frac{I_{p h}+I_{O}}{I_{O}}
$$

where $I . R_{s} \approx 0$ and $a=1$ are used.

Table I. Electrical Data PV Panel at STC

\begin{tabular}{|l|c|c|}
\hline Maximum power (+5/-3\%) & $P_{M A X}$ & $210 \mathrm{~W}$ \\
\hline Voltage at MPP & $V_{M P P}$ & $40.0 \mathrm{~V}$ \\
\hline Current at MPP & $I_{M P P}$ & $5.25 \mathrm{~A}$ \\
\hline Open Circuit Voltage & $V_{O C}$ & $47.7 \mathrm{~V}$ \\
\hline Short Circuit Current & $I_{S C}$ & $5.75 \mathrm{~A}$ \\
\hline Limiting Reverse Current & $I_{R}$ & $14.4 \mathrm{~A}$ \\
\hline
\end{tabular}

A model based on the equations for the PV panel is built and implemented in MATLAB. Table I tabulates the parameters of a PV panel simulated as an example in this paper. The numerical simulation results show that when the temperature increases, $I_{S C}$ increases while $V_{O C}$ decreases, and the maximum power diminishes. On the other hand, at the different radiations, by reducing the solar radiant, $G, I_{S C}$ can be significantly reduced while $V_{O C}$ is reduced slightly in the I$\mathrm{V}$ curve, and the maximum power is reduced, as shown in Fig. 3 where the temperature is set at $25^{\circ} \mathrm{C}$. 


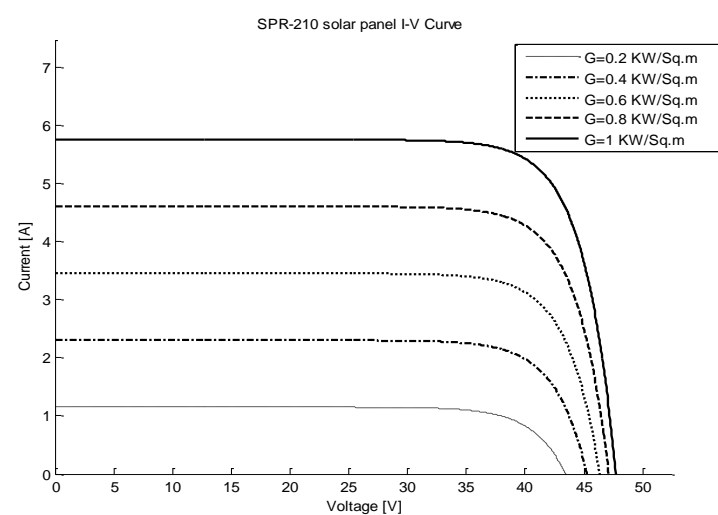

(a) I-V Curve

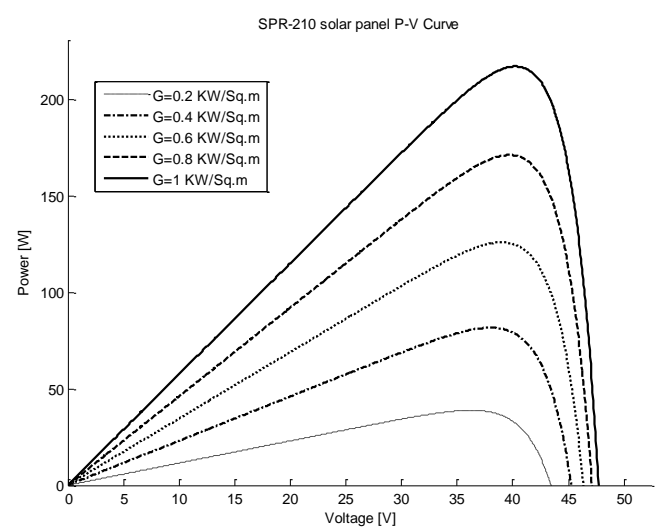

(b) P-V Curve

Figure 3. I-V Curve and P-V Curve at $25^{\circ} \mathrm{C}$

\section{THE DC-DC BUCK-BOOST CONVERTER}

\section{A. DC-DC Buck-Boost Converter}

There are several topologies of DC-DC converters commonly used in PV systems [9]. In this paper, the buckboost configuration is chosen for the power circuit of maximum power point tracker, since the output voltage can be larger or smaller than the input voltage and also they have opposite polarity without a transformer. Moreover, it provides high efficiency and is easy to implement. The output voltage can be calculated as,

$$
V_{O}=-\frac{D}{1-D} V_{\text {in }}
$$

where $\mathrm{D}$ is the duty cycle of converter. The negative sign demonstrates the opposite polarity between the output and input voltages. The output voltage ripple can be obtained as,

$$
\frac{\Delta V o}{V o}=\frac{D}{R f C}
$$

which is the same as that in the boost topology. At the boundary between the continuous and discontinuous inductor current, the minimum inductance should be

$$
L_{\text {min }}=\frac{(1-D)^{2} \cdot R}{2 f}
$$

Fig.4 depicts the SIMULINK model of the buck-boost converter.

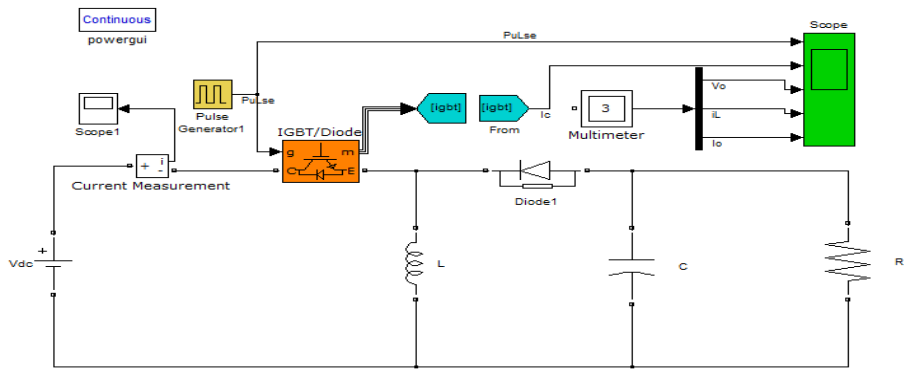

Figure 4. Buck-boost converter

\section{B. Impedance Control Converter}

The impedance control is used to ensure that a model works at MPP and tracks it precisely. Assuming that the converter is an ideal and loss-less one, we have

$$
P_{O}=P_{I N}
$$

and the input impedance can be computed as,

where $R_{\text {Load }}=\frac{V_{O}}{I_{O}}$.

$$
R_{I N}=\frac{(1-D)^{2}}{D^{2}} \cdot R_{\text {Load }}
$$

In order to deliver the MPP to the load, the input impedance should be same as the optimal one, $\mathrm{R}_{\mathrm{OPT}}$, which is defined as the impedance that makes system work at the MPP, and can be calculated by

$$
R_{O P T}=\frac{V_{M P P}}{I_{M P P}}
$$

and the corresponding duty ratio is

$$
D=\frac{1}{1+\sqrt{\frac{R_{\text {OPT }}}{R_{\text {Load }}}}}
$$

As shown in Fig.5, the crossing point of the optimal I-V load line and PV module gives us the MPP. Note that there is one matched load for every $T$ and $G$.

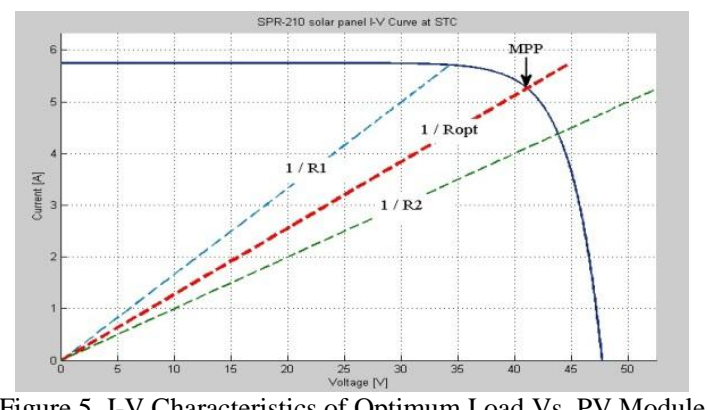

Figure 5. I-V Characteristics of Optimum Load Vs. PV Module

\section{ADAPTIVE NEURO-FUZZY CONTROLLER}

Fig.6 depicts the block diagram of the proposed MPPT Controller. The objective of the controller is to determine the duty cycle, D, of the converter, by which the converter delivers the maximum attainable power to the load at any given temperature and irradiance. Controller generates PWM signal for the converter. The first part of the controller, Adaptive Neuro-Fuzzy Inference System (ANFIS), works as a reference model of the PV array and finds the suitable maximum voltage under a given temperature and irradiance while the FL controller produces the change of $\mathrm{D}$ by 
comparing the maximum voltage of reference model and the output voltage of the PV array.

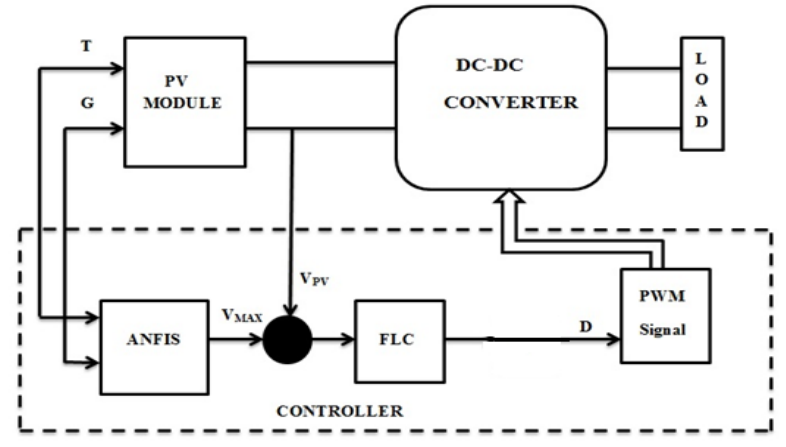

Figure 6. Proposed MPPT

\section{A. Fuzzy Inference System (FIS)}

Every FIS model is composed of three stages as shown in Fig.7. In fuzzification stage, FIS maps the input variables to linguistic variables by determining the membership function (MF). After that, the IF-THEN rules are provided to set a relationship among the inputs and the output, which is called rule evaluation. Then, in defuzzification, the linguistic variables are converted to a crisp value of output. The parameters are tuned according to the input-output data of model [7].

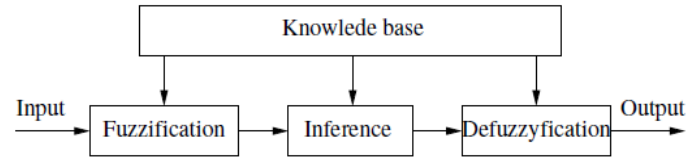

Figure 7. Fuzzy Inference System

\section{B. Fuzzy Logic Contrller}

In general, the fuzzy logic controller (FLC) is a FIS [10]. The first part is fuzzification, which is a procedure of converting numerical inputs into linguistic variables according to the degree of membership function. The linguistic variables are defined as Negative Large (NL), Negative Medium (NM), Negative Small (NS), Zero (Z), Positive Small (PS), Positive Medium (PM), and Positive Large (PL). Each of them shows the fuzzy value of input data, as can be seen in Fig.8.

The membership functions (MFs) can be an arbitrary curve whose shape can be defined as a function that suits designers in approaching of simplicity, convenience, speed, and efficiency. MFs for ANFIS and FLC are chosen Gaussian and triangular function respectively. The Gaussian MF has the advantage of being smooth and nonzero at all points, while the triangular MF is used because of its simplicity.

It is a general view that if the number of MFs between the defined ranges is larger, then the possible rules increases and the response will be worthy. It is desirable to increase the rules for a proper response but after increasing the rules to a certain limit (49 rules in this case) there is no need to go beyond since the response does not change appreciably.

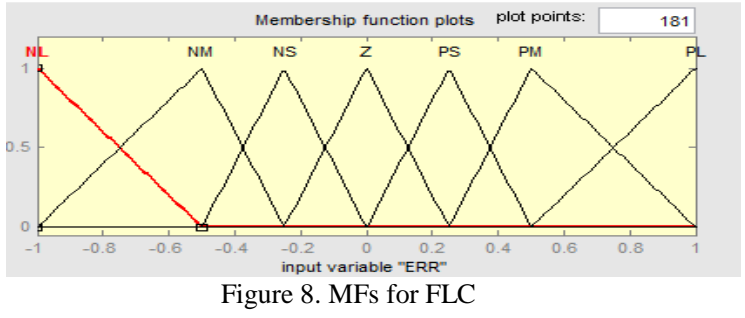

There are two common inputs for FLC, error ' $\mathrm{E}$ ' and change in error ' $\Delta \mathrm{E}$ ', as follows,

$$
\begin{gathered}
\mathrm{E}=\mathrm{V}_{\mathrm{MAX}}-\mathrm{V}_{\mathrm{PV}} \\
\Delta \mathrm{E}(\mathrm{n})=\mathrm{E}(\mathrm{n})-\mathrm{E}(\mathrm{n}-1) .
\end{gathered}
$$

The output of FLC generally is $\Delta D$, change in duty ratio, of the power converter. Table II shows the second stage of FLC known as the rule based table lookup. The rules explain the relationship among $E, \Delta E$ and $\Delta D$ represented by IFTHEN sentences. For example, if error is negative small (NS) and change of error is positive small (PS) then change of duty cycle will be zero $(\mathrm{Z})$.

The third level of FLC is defuzzification in which numerical variables and result will be produced to provide the analog signal that controls MPP.

Table II. Fuzzy Rules

\begin{tabular}{|c|c|c|c|c|c|c|c|}
\hline$E \backslash E$ & NL & NM & NS & Z & PS & PM & PL \\
\hline NL & NL & NL & NL & NL & NM & NS & Z \\
\hline NM & NL & NL & NL & NM & NS & Z & PS \\
\hline NS & NL & NL & NM & NS & Z & PS & PM \\
\hline Z & NL & NM & NS & Z & PS & PM & PL \\
\hline PS & NM & NS & Z & PS & PM & PL & PL \\
\hline PM & NS & Z & PS & PM & PL & PB & PL \\
\hline PL & Z & PS & PM & PL & PL & PL & PL \\
\hline
\end{tabular}

\section{Adaptive Neuro-Fuzzy Inference System (ANFIS))}

The neuro-fuzzy inference is a combination of ANN and FL. The ANN identifies the patterns and conforms to them to deal with altering environments. On the other hand, the fuzzy inference systems (FIS) combine the human knowledge and carry out the inference and process of decision making [3]. Two common fuzzy models, the Mamdani and TakagiSugeno-Kang (TSK), are defined for FIS.

The ANFIS is only able to use the TSK fuzzy model due to its high calculative efficiency, adaptive techniques and built in optimum. The controller provides smoothness in convergence because of the fuzzy TSK inference and adaptability as a result of ANN back propagation algorithms [11]. The structure of a typical five layer ANFIS system is illustrated in Fig.9

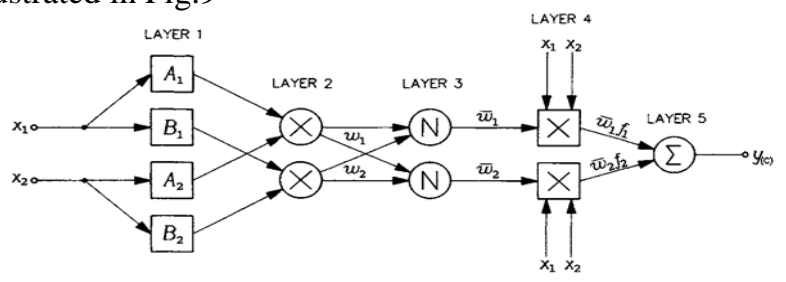

Figure 9. A typical five layer ANFIS System 
In the first layer, MFs will be defined for each of inputs. In the second layer, each node via multiplication calculates the firing strength of a rule. The firing strength is normalized in LAYER 3. Two common rules in TSK fuzzy model are defined as

Rule 1: if $x_{1}$ is $A_{1}$ and $x_{2}$ is $A_{2}$, then $f_{1}=a_{1} x_{1}+b_{1} x_{2}+c_{1}$

Rule 2: if $x_{1}$ is $B_{1}$ and $x_{2}$ is $B_{2}$, then $f_{2}=a_{2} x_{1}+b_{2} x_{2}+c_{2}$ where $a_{i}, b_{i}$, and $c_{i}$ are the design parameters defined in the training plant. Also $A_{i}$ and $B_{i}$ are the fuzzy sets input [12].

In MATLAB, a structure of the model is determined by using the inputs, output, MFs, and the relationship among them. After that, the inputs and output training data set should be collected to train the ANFIS. In fact the ANFIS can estimate the MF's parameters by either back propagation algorithms alone or the so-called hybrid mode which is a combination of least squares estimation (LSE) and back propagation.

Data for the ANFIS inputs are collected from the PV module I-V characteristics. Temperature (T) varies from 0 to $45^{\circ} \mathrm{C}$ in a step of $5^{\circ} \mathrm{C}$ and solar radiant $(\mathrm{G})$ is between 200 to $1000 \mathrm{~W} / \mathrm{m} 2$ in a step of $50 \mathrm{~W} / \mathrm{m} 2$. The number of total data sets is 170 in which two third of data sets are used for training the network and the remaining are used for checking data. The training is done offline using ANFIS tool box in MATLAB. The network is trained for 150 epochs and the target error is set to $6 \%$. The training error waveform is depicted in Fig.10, and the structure of ANFIS for this controller is shown in Fig.11. As can be seen in Figs.12 and 13, the fuzzy rules for the ANFIS inputs and output are applied after training and also surface of the system is provided, respectively. The advantages of the method are its rapid tracking speed and high tracking accuracy.

\section{Simulation Results}

In order to evaluate the performance of the proposed MPPT scheme, a numerical simulation study is carried out by using the MATLAB model as shown in Fig.14. Here, a case study is considered where irradiance is changing in time while the temperature is kept constant at $30^{\circ} \mathrm{C}$ as shown in Fig.15(a). The irradiance is altered every one second. These changes can show us how the system works. As can be seen by changing the irradiation for every second the new duty cycle (Fig.15(b)) will be produced by the controller for the buck-boost converter. Then, the new maximum voltage and power will be obtained (Fig.15(c)).

Compared with the FLC method, the ANFIS controller is faster and more stable than the FLC. In the simulation, the buck-boost converter shows good performances when the controller works under different conditions. When the weather conditions change, the controller can track the new MPP corresponding to the new solar insolation.

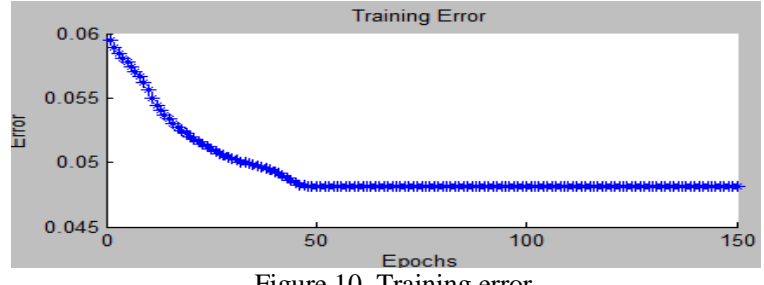

Figure 10. Training error

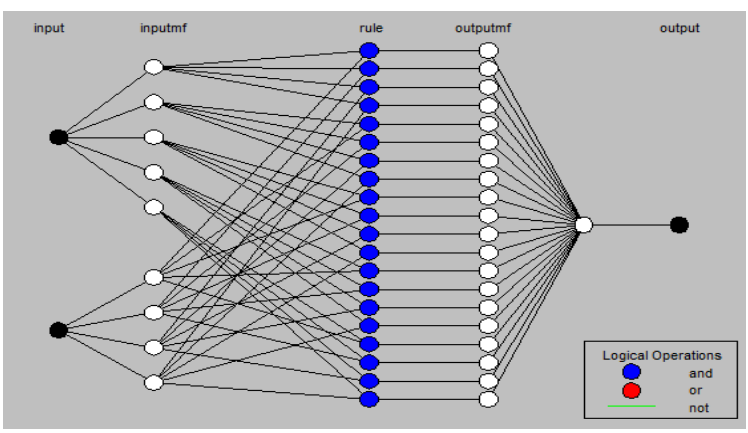

Figure 11. ANFIS System
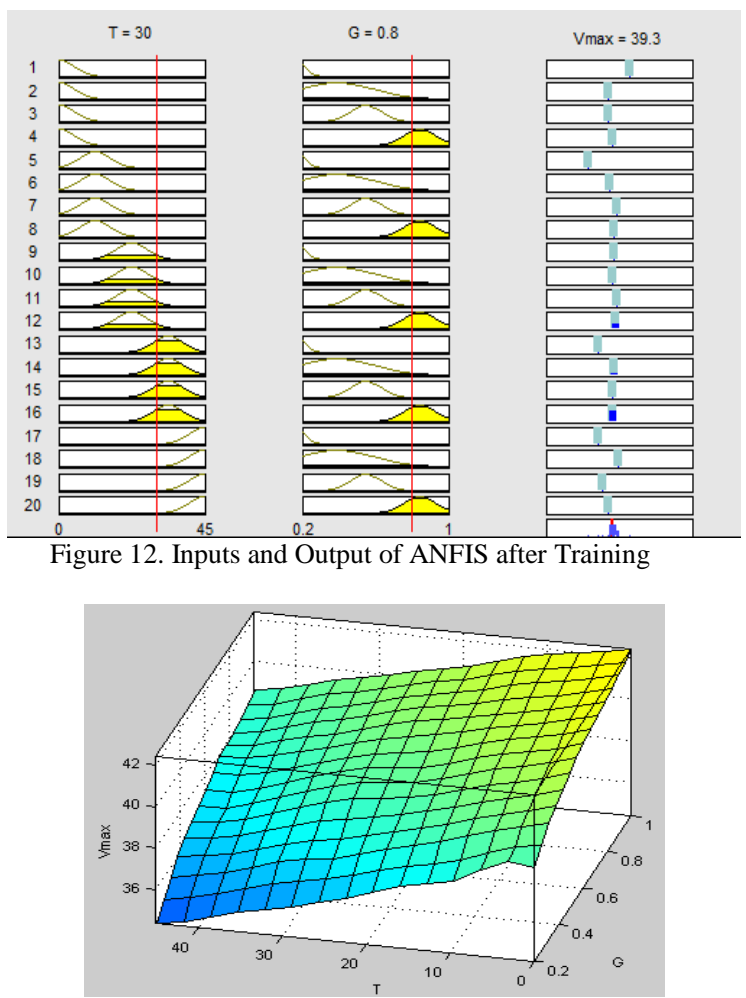

Figure 13. Surface of the System for ANFIS

\section{CONCLUSION AND FUTURE WORK}

The simulation results indicate that an intelligent controller is able to tune the system parameters and obtain good results under all weather conditions. This controller gives a better output value for buck-boost converter than the commonly used boost converter. This type of controller, compared with other methods, is simpler to understand, and implement, because it is an inference system with rules in linguistic terms. Because, it is a rule based system, it applies to nonlinear systems as well. 


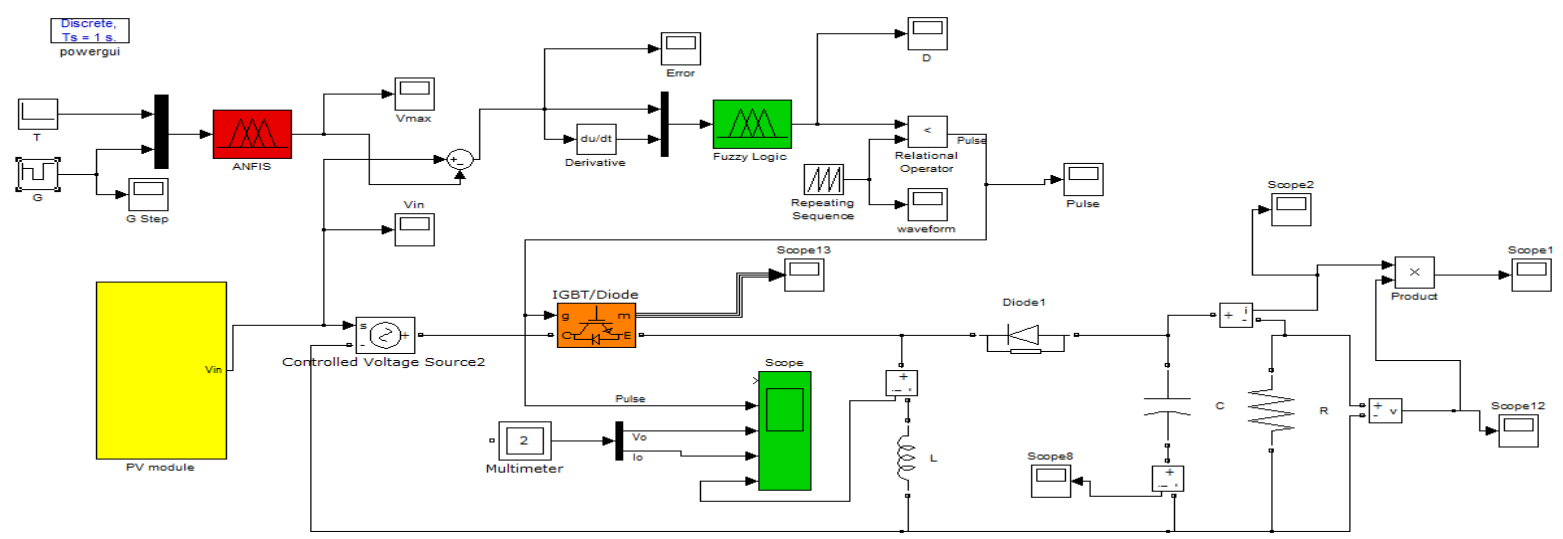

Figure 14. Proposed Model in SIMULINK

It should be pointed out that some parameters are omitted in the current work in order to simplify the case. For example, the shunt resistance in PV model is not considered. The weather condition is another parameter which should be taken into account, especially in partially shaded or uncertain conditions. In the future work, these parameters will be used to build a more comprehensive and accurate model.

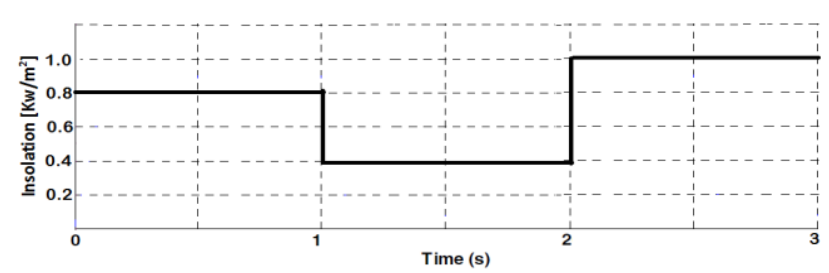

(a) Irradiance $\left(\frac{K W}{m^{2}}\right)$

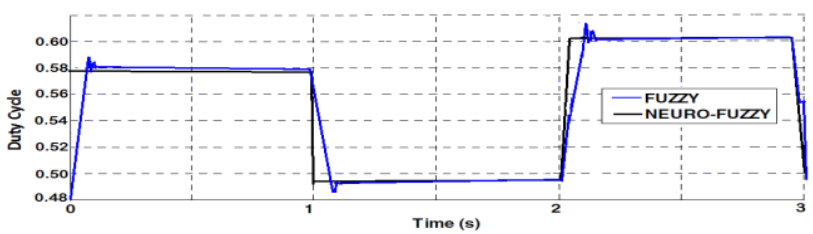

(b) Duty Cycle

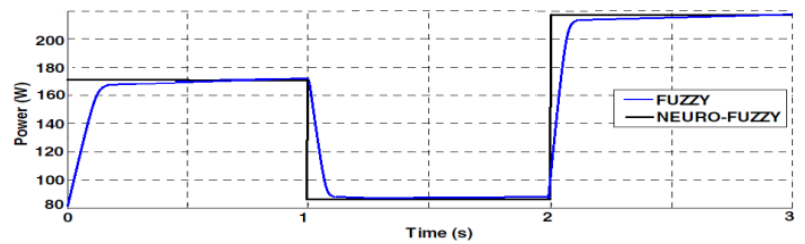

(c) Output Power (W)

Figure 15. Simulation Results

\section{REFERENCES}

[1] B. Khan, Non-conventional energy resources: Tata McGraw-Hill Education, 2006.

[2] D. Radianto, D. Anton Asfani, and T. Hiyama, "Fuzzy Logic Controller Based Maximum Power Point Tracking for Total Cross Tied Photovoltaic Under Partial Shading,", 2013.

[3] T. Esram and P. L. Chapman, "Comparison of photovoltaic array maximum power point tracking techniques," IEEE TRANSACTIONS ON ENERGY CONVERSION EC, vol. 22, p. 439, 2007.

[4] M. S. Ngan and C. W. Tan, "A study of maximum power point tracking algorithms for stand-alone photovoltaic systems," in Applied Power Electronics Colloquium (IAPEC), 2011 IEEE, 2011, pp. 22-27.

[5] A. R. Reisi, M. H. Moradi, and S. Jamasb, "Classification and comparison of maximum power point tracking techniques for photovoltaic system: A review," Renewable and Sustainable Energy Reviews, vol. 19, pp. 433-443, 2013.

[6] B. Subudhi and R. Pradhan, "A comparative study on maximum power point tracking techniques for photovoltaic power systems," Sustainable Energy, IEEE Transactions on, vol. 4, pp. 89-98, 2013.

[7] A. Mellit and S. A. Kalogirou, "Artificial intelligence techniques for photovoltaic applications: A review," Progress in energy and combustion science, vol. 34, pp. 574-632, 2008.

[8] M. S. Benghanem and S. N. Alamri, "Modeling of photovoltaic module and experimental determination of serial resistance," Journal of Taibah University for science, vol. 2, pp. 94-105, 2009.

[9] M. Gaboriault and A. Notman, "A high efficiency, noninverting, buckboost DC-DC converter," in Applied Power Electronics Conference and Exposition, 2004. APEC'04. Nineteenth Annual IEEE, 2004, pp. 14111415.

[10] C. S. Chin, P. Neelakantan, H. P. Yoong, and K. T. K. Teo, "Optimisation of fuzzy based maximum power point tracking in PV system for rapidly changing solar irradiance," Transaction on Solar Energy and Planning, vol. 2, 2011.

[11] C. A. Otieno, G. N. Nyakoe, and C. W. Wekesa, "A neural fuzzy based maximum power point tracker for a photovoltaic system," in AFRICON, 2009. AFRICON'09., 2009, pp. 1-6.

[12] M. A. Denaï, F. Palis, and A. Zeghbib, "Modeling and control of nonlinear systems using soft computing techniques," Applied Soft Computing, vol. 7, pp. 728-738, 2007. 